
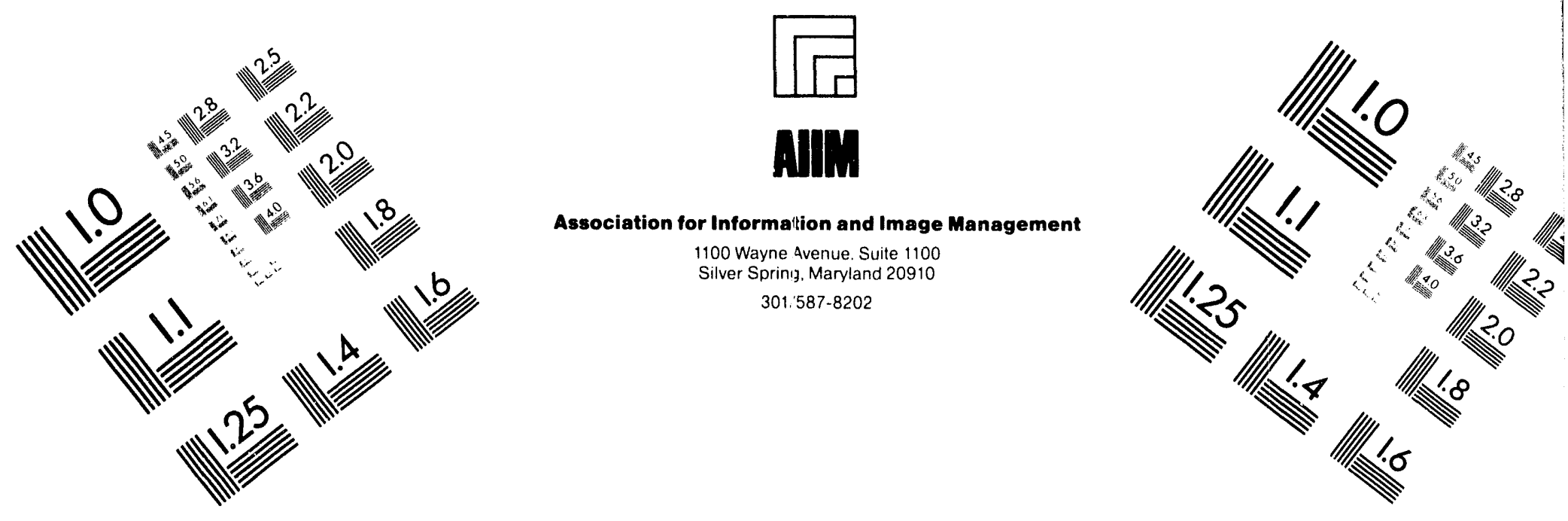

\title{
Centimeter
}

1m Inches
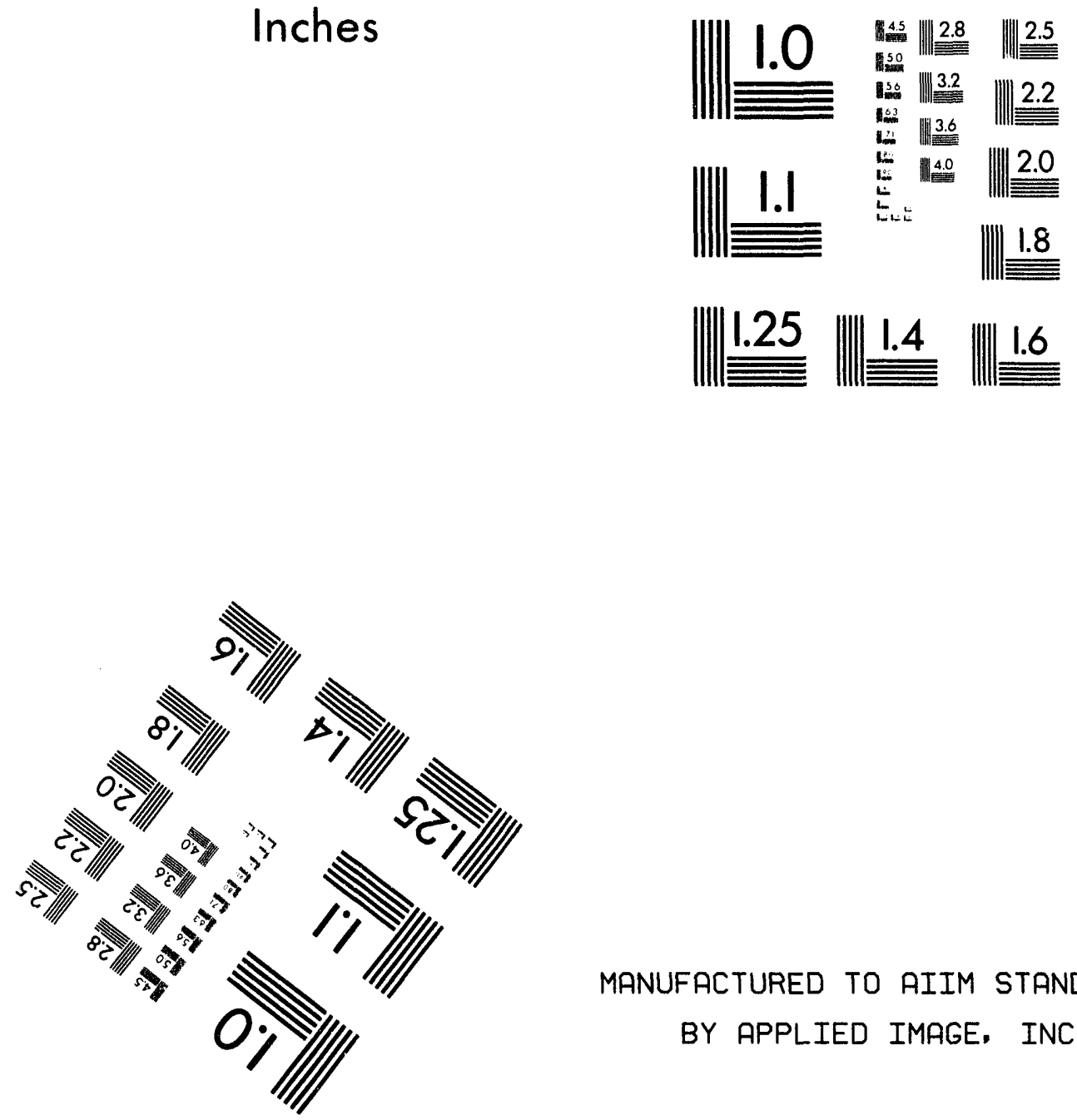

MANUFACTURED TO AIIM STANDARDS

BY APPLIED IMAGE, INC.

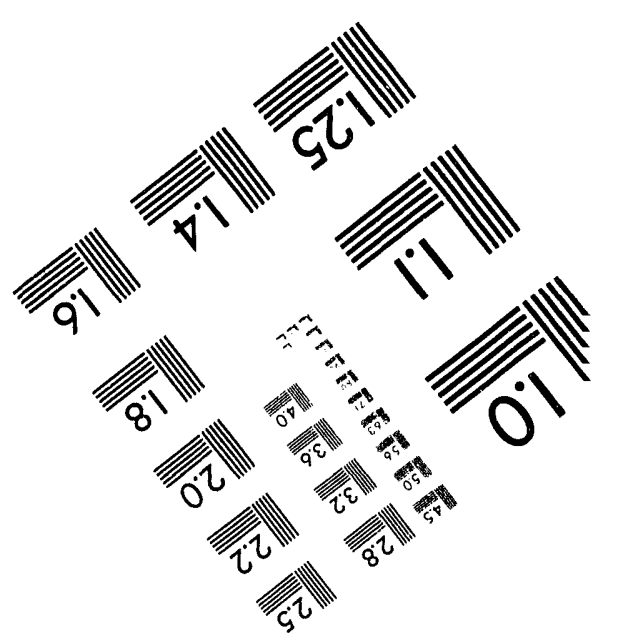



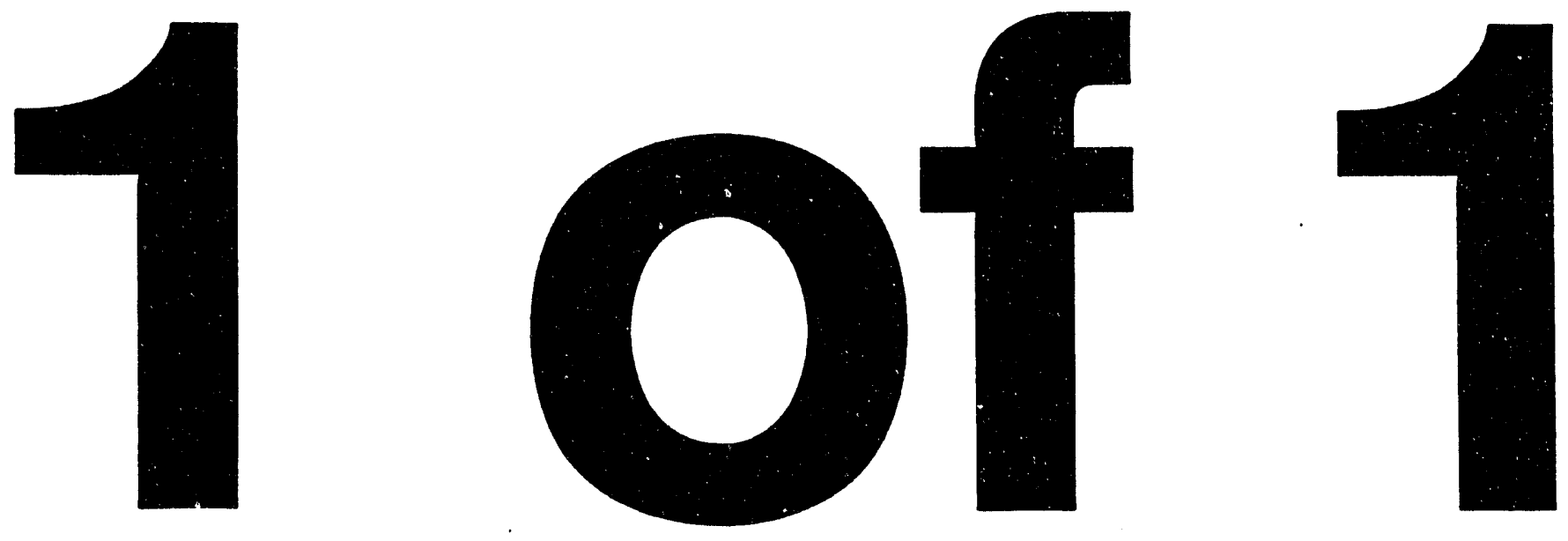


\title{
Conf-94066107..4 \\ PNL-SA-24153
}

\section{DOSIMETRY OF INHALED RADON AND THORON PROGENY}

A. C. James

June 1994

\section{DISCLAIMER}

\begin{abstract}
This report was prepared as an account of work sponsored by an agency of the United States Government. Neither the United States Government nor any agency thereof, nor any of their employees, makes any warranty, express or implied, or assumes any legal liability or responsibility for the accuracy, completeness, or usefulness of any information, apparatus, product, or process disclosed, or represents that its use would not infringe privately owned rights. Reference herein to any specific commercial product, process, or service by trade name, trademark, manufacturer, or otherwise does not necessarily constitute or imply its endorsement, recommendation, or favoring by the United States Government or any agency thereof. The views and opinions of authors expressed herein do not necessarily state or reflect those of the United States Government or any agency thereof.
\end{abstract}

Presented at the Health Physics Society 1994 Summer School June 20-24, 1994 Davis, California

Prepared for

the U.S. Department of Energy under Contract DE-AC06-76RLO 1830

Pacific Northwest Laboratory

Richland, Washington 99352 
For publication in Internal Radiation Dosimetry (Ed. O. G. Raabe), Proceedings of the 1994 Health Physics Society Summer School, University of California, Davis, June 20 - 24, 1994.

\title{
DOSIMETRY OF INHALED RADON AND THORON PROGENY
}

\author{
Anthony C. James \\ Pacific Northwest Laboratory \\ Richland, Washington
}

\section{ABSTRACT}

This chapter reviews recent developments in modeling doses received by lung tissues, with particular emphasis on application of ICRP's new dosimetric model of the respiratory tract for extrapolating to other environments the established risks from exposure to radon progeny in underground mines. Factors discussed include: (1) the influence of physical characteristics of radon progeny aerosols on dose per unit exposure, e.g., the unattached fraction, and the activitysize distributions of clustered and attached progeny; (2) the dependence of dose on breathing rate, and on the exposed subject (man, woman or child); (3) the variability of dose per unit exposure in a home when exposure is expressed in terms of potential $\alpha$ energy or radon gas concentration; (4) the comparative dosimetry of thoron progeny; and (5) the effects of aircleaning on lung dose. Also discussed is the apparent discrepancy between lung cancer risk estimates derived purely from dosimetry and the lung cancer incidence observed in the epidemiological studies of radon-exposed underground miners. Application of ICRP's recommended risk factors appears to ovestimate radon lung-cancer risk for miners by a factor of three. "Normalization" of the calculated effective dose is therefore needed, at least for $\alpha$ dose from radon and thoron progeny, in order to obtain a realistic estimate of lung cancer risk. 


\section{INTRODUCTION}

Exposure of uranium and other undergound miners to radon progeny (mainly in the 1950s and 1960s) has been shown to have caused more than 1,000 lung cancers (Lubin et al., 1994). Based on these epidemiological studies, the ICRP has accordingly recommended in Publication 65 (ICRP, 1994a) a reasonably firm (rounded) estimate of the increased lifetime risk of lung cancer of $310^{-4}$ per Working Level Month (WLM ${ }^{1}$ ). ICRP derived this value for their "reference population" (a mixed population of smokers and nonsmokers) which has baseline values of survival probability, and of age-specific lung cancer mortality rate averaged from the populations of Japan, the United States, Puerto Rico, the United Kingdom and China (Land and Sinclair, 1991). Strictly, the risk of $310^{-4}$ per WLM applies for males exposed at a constant rate over their working lifetime (from age 18 to 64 years), but for practical purposes ICRP assumes that the same value applies for female workers.

On comparing the risk factor of $310^{-4}$ per WLM of radon progeny exposure with the reference risk factor for occupational exposure of $5.610^{-5} \mathrm{per} \mathrm{mSv}$ of effective dose (ICRP, 1991), it is seen that exposure to 1 WLM implies the same risk as $5 \mathrm{mSv}$ of effective dose. ICRP (1994a) uses this so-called "conversion convention" between radon progeny exposure and effective dose to translate their basic recommendations on limiting annual exposure at work into practical limits on radon progeny "exposure." Thus, the recommended dose limit of $20 \mathrm{mSv}$ per year averaged over a period of 5 years, with the proviso that the effective dose should not exceed $50 \mathrm{mSv}$ in any single year (ICRP, 1991), is translated into a radon progeny exposure limit of 4 WLM per year averaged over 5 years and 10 WLM in a single year (ICRP, 1994a).

ICRP assumes that the risk factor of $310^{-4}$ per WLM of radon progeny exposure also applies for lifetime exposure in the home (ICRP, 1994a). Accordingly, the reference dosimetric risk

${ }^{1}$ One Working Level (WL) equals any combination of radon progeny in one liter of air which results in the ultimate emission of $1.310^{5} \mathrm{MeV}$ of energy from $\alpha$ particles (termed potential $\alpha$ energy). The WLM is a time-integrated exposure and is the product of time, in units of working months (taken to be 170 hours), and WL. 
factor for the general public of $7.310^{-5}$ per $\mathrm{mSv}$ of effective dose (ICRP, 1991) leads to a somewhat lower "conversion convention" of approximately $4 \mathrm{mSv} / \mathrm{WLM}$ for exposure in the home (ICRP, 1994a). Based on their judgement that the annual effective dose in a home should not be higher than $3-10 \mathrm{mSv} / \mathrm{y}$, ICRP then uses this conversion convention to derive recommended values of annual exposure to radon progeny (or corresponding values of annual exposure to radon gas) at which "action" should be taken to reduce exposure.

These recommendations in ICRP Publication 65 do not explicitly require tissue doses from exposure to radon and its progeny to be evaluated. However, ICRP's assumption that the lung cancer risk per unit exposure in a home is the same as that in an underground uranium in effect implies that the equivalent doses to lung tissues are the same (per unit exposure). Likewise, by setting exposure limits for occupational exposure that are based entirely on observations of lung cancer incidence in underground uranium miners, it is implied that the dose per unit radon progeny exposure in all workplaces is similar to that received historically in 1950s and 1960s mines. The current role of internal ."dosimetry" in relation to protection against radon progeny at home and at work is to determine the degree to which exposure standards based directly on uranium miner epidemiology need to be modified to take account of different exposure conditions (NRC, 1991).

This chapter briefly reviews recent developments in modeling doses received by lung tissues in relation to: (1) the physical characteristics of radon progeny aerosols, e.g., unattached fraction, and the activity-size distribution of attached progeny; (2) the dependence of dose per unit exposure on breathing rate, and on the exposed subject (man, woman or child); and (3) the variability of dose per unit exposure in a home (expressed in terms of both progeny and radon gas concentrations). The new dosimetric model of the respiratory tract recommended by ICRP in Publication 66 is used here to carry out these analyses.

In addition to providing practical insights that can be used for refining standards of protection against radon progeny at home and at work, lung dosimetry is useful to: 
derive limits for exposure to thoron progeny (for which there are no epidemiological data);

examine how well ICRP's recommended dosimetric risk factors, which are based on lung cancer incidence in the Japanese atomic bomb survivors (ICRP, 1991) and fundamental radiobiological assumptions, are able to predict the lung cancer incidence in uranium miners that is caused by radon-progeny $\alpha$ irradiation; and

evaluate the potential benefits of measures to reduce exposure to radon progeny, for example, by air cleaning.

The implications of the new ICRP lung dosimetry with reference to these topics are also discussed.

\section{DEPENDENCE OF LUNG DOSE ON RADON PROGENY PARTICLE SIZE}

Figure 1 shows the regionally apportioned lung dose for exposure to radon-progeny potential $\alpha$ energy, in mGy per Working Level Month (WLM), given as a function of particle size by the new ICRP Publication 66 lung model. This so-called "dose conversion factor" (DCF) was calculated for a resting adult male (with a characteristic breathing rate of $0.54 \mathrm{~m}^{3} \mathrm{~h}^{-1}$ ). The "regionally apportioned" lung dose is obtained by taking the average of the doses calculated for the three sensitive regions of the lungs; the bronchial and bronchiolar epithelia, and the alveolarinterstitial tissues. The figure compares this dose to the lungs as a whole with values modeled previously for just bronchial epithelium (NRC 1991; N. H. Harley, personal communication 1991). For "unattached" radon progeny (which are actually progeny atoms associated with other atoms or molecules to form a particle of about $0.001 \mu \mathrm{m}$ in diameter), the regionally apportioned lung dose is significantly lower than the values calculated for bronchial epithelium. However, for progeny associated with larger "clusters" of molecules (of about $0.01 \mu \mathrm{m}$ overall diameter), and for progeny attached to particles up to about $1 \mu \mathrm{m}$ in diameter, the regionally apportioned 
lung dose is similar to that calculated for bronchial epithelium. The calculated doses are relatively independent of which dosimetric model is used.

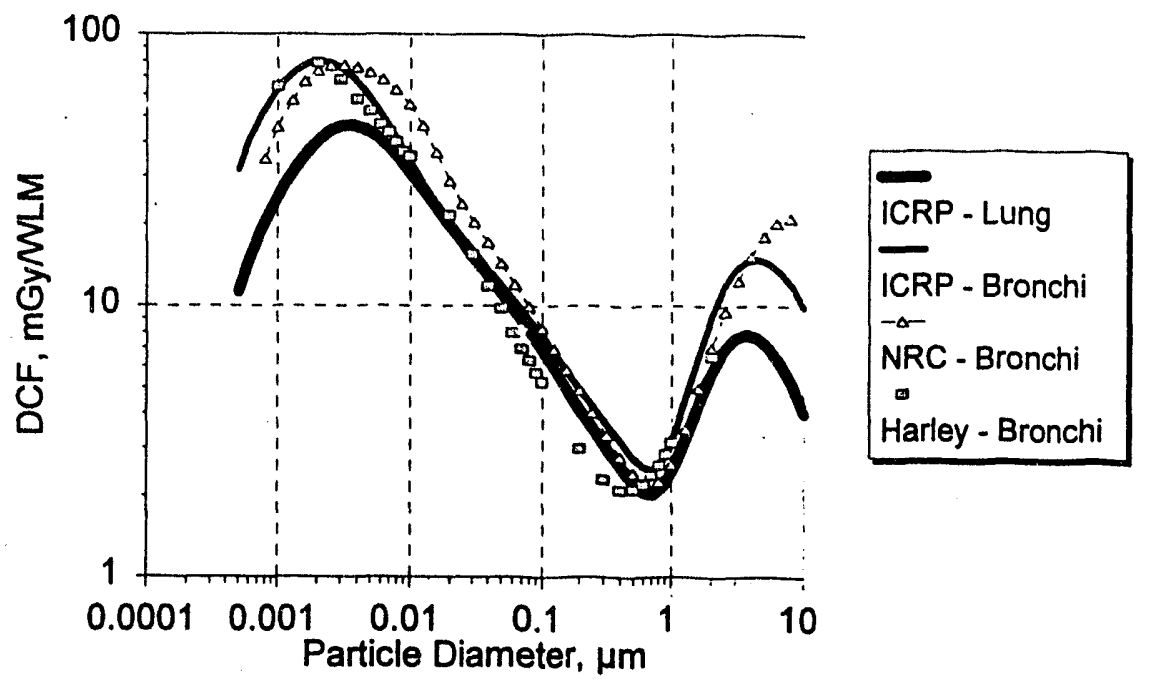

FIGURE 1. Dependence of dose per unit exposure (i.e., the dose conversion factor, DCF) on dosimetry model and extent of target tissue considered, shown as a function of radon-progeny particle diameter.

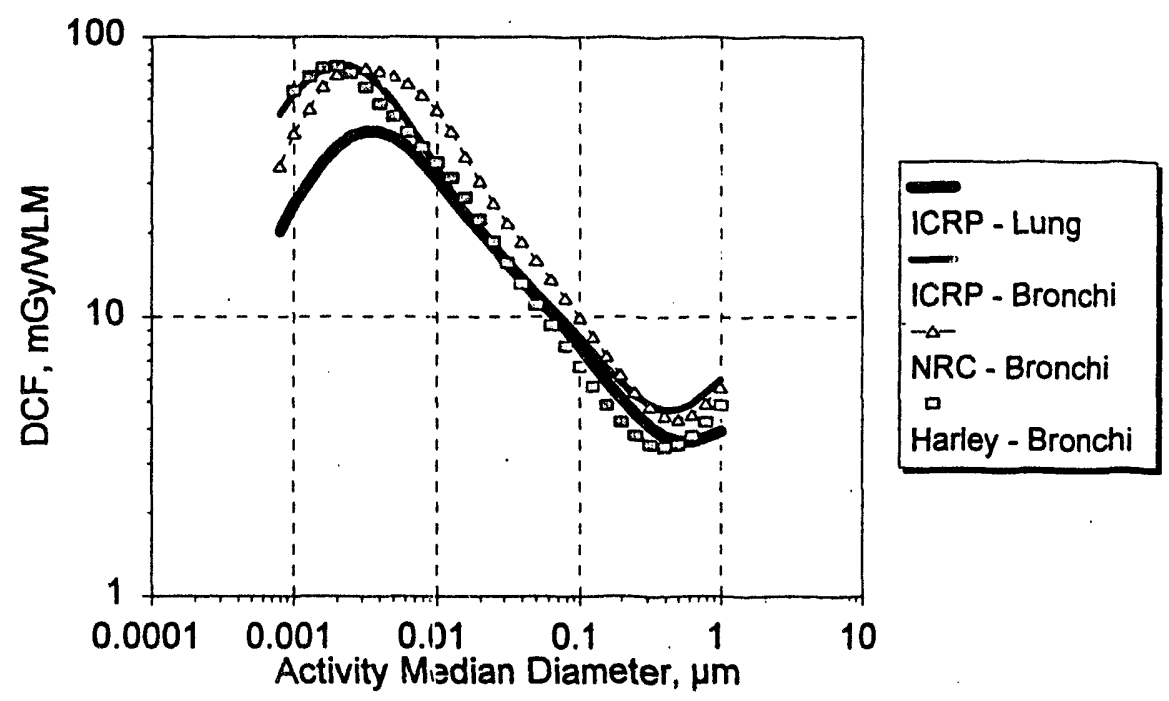

FIGURE 2. Dependence of dose corversion factors (DCFs) on the activity median diameter of a radon-progeny aerosol. 
Whether in a mine or in a home, airborne radon progeny are carried by particles which vary widely in size. The resulting dose per unit exposure then depends primarily on the "median" size of the carrier particles; the geometric standard deviation in particle size, $\sigma_{\mathrm{g}}$, usually increases from about unity for "unattached" progeny of about $0.001 \mu \mathrm{m}$ in diameter to about 2.5 for "attached" progeny aerosols. For these attached aerosols, the presence of particles substantially smaller or larger than the median size has the effect of raising the minimum value of the DCF from about $2 \mathrm{mGy} / \mathrm{WLM}$ (Figure 1) to about $3 \mathrm{mGy} / \mathrm{WLM}$, as shown in Figure 2.

\section{DEPENDENCE ON BREATHING RATE}

Figure 3 shows the degree to which the DCF depends on a subject's breathing rate. The ratios of DCFs are calculated for an adult male as a function of the activity median diameter of the radon progeny aerosol, for two different breathing rates, and shown normalized to the corresponding values (unity) calculated for a "reference worker." The breathing rate of the reference worker is taken to be $1.2 \mathrm{~m}^{3} \mathrm{~h}^{-1}$ (ICRP, 1994b). The two breathing rates compared in the figure are that appropriate for "heavy work, "i.e., $1.7 \mathrm{~m}^{3} \mathrm{~h}^{-1}$, and the "average at home" which, including 8 hours of sleep, is taken to be $0.78 \mathrm{~m}^{3} \mathrm{~h}^{-1}$.

For "unattached" radon progeny (of diameter about $0.001 \mu \mathrm{m}$ ), the DCF is approximately proportional to the breathing rate. For progeny "clusters" (of diameter on the order of $0.01 \mu \mathrm{m}$ ) through "attached" progeny aerosols with activity median diameter up to about $0.1 \mu \mathrm{m}$, the DCF is approximately proportional to the square root of the breathing rate. As the aerosol size increases further, particularly for high breathing rates, the DCF changes more rapidly (again approximately in proportion to the breathing rate again). 


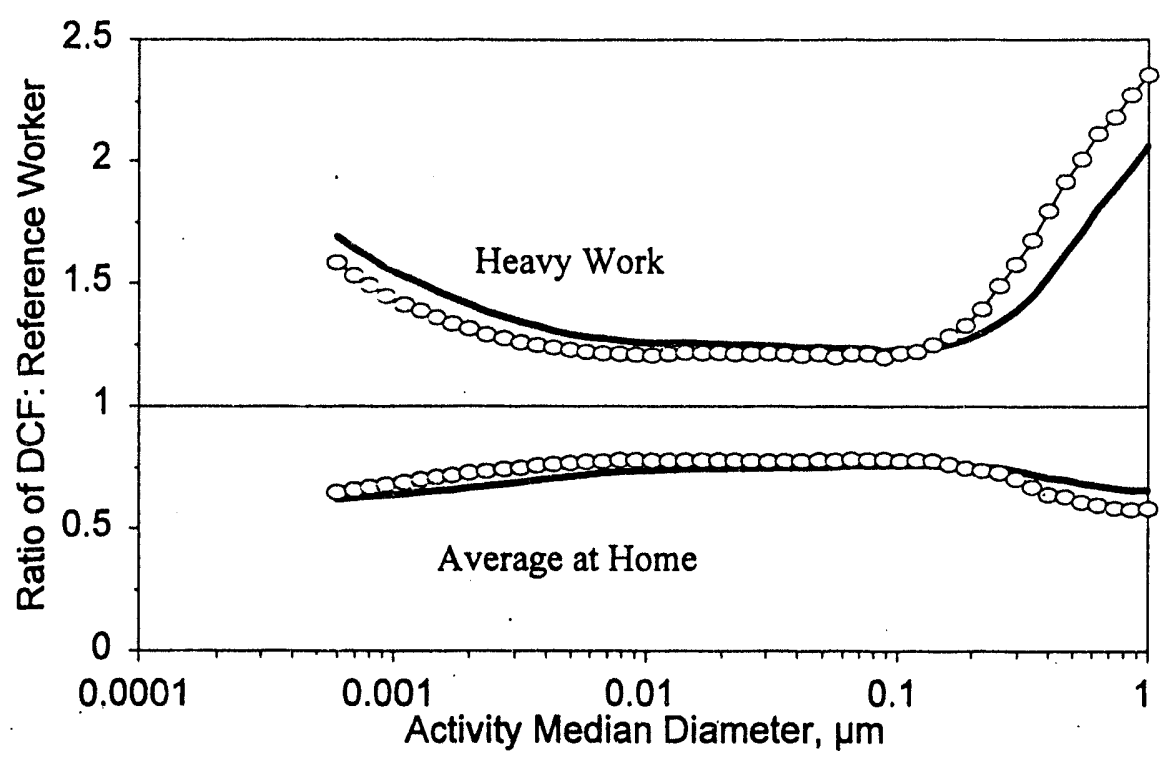

Lungs -o- Bronchi

FIGURE 3. Dependence of the DCF on breathing rate. The ratio of the DCF calculated for two different levels of physical activity with respect to that calculated for a "reference worker" is shown as a function of the activity median diameter of a radon progeny aerosol.

\section{DEPENDENCE ON SUBJECT}

Figure 4 compares DCFs calculated for women and children with that calculated for an adult male, all as a function of the activity median diameter of radon progeny aerosols. In this figure, the DCF calculated for each subject is shown as a multiple of the corresponding value calculated for an adult male. For each subject, the average breathing rate for indoor exposure at home was assumed. These values are: $0.78 \mathrm{~m}^{3} \mathrm{~h}^{-1}$ for the adult male; $0.69 \mathrm{~m}^{3} \mathrm{~h}^{-1}$ for the adult female, and; $0.56,0.32,0.19$ and $0.12 \mathrm{~m}^{3} \mathrm{~h}^{-1}$ for children aged 10,5 and $1 \mathrm{y}$, and $3 \mathrm{mo}$, respectively (ICRP, 1994b). It is seen that the DCF differs only slightly between men, women and children, at least down to the age of $10 y$. In younger children, the DCF is substantially different from that calculated for the adult male only for very small particles ("unattached" progeny) and for "attached" progeny aerosols larger than about $0.3 \mu \mathrm{m}$ in activity median diameter. At these 
extremes, the DCF calculated for young children is lower than that for older subjects (primarily because of the former group's higher nasal filtration efficiency). Clearly, therefore, young children are not at greater risk than adults when exposed to radon in the home, at least in regard to lung tissue dose rate.

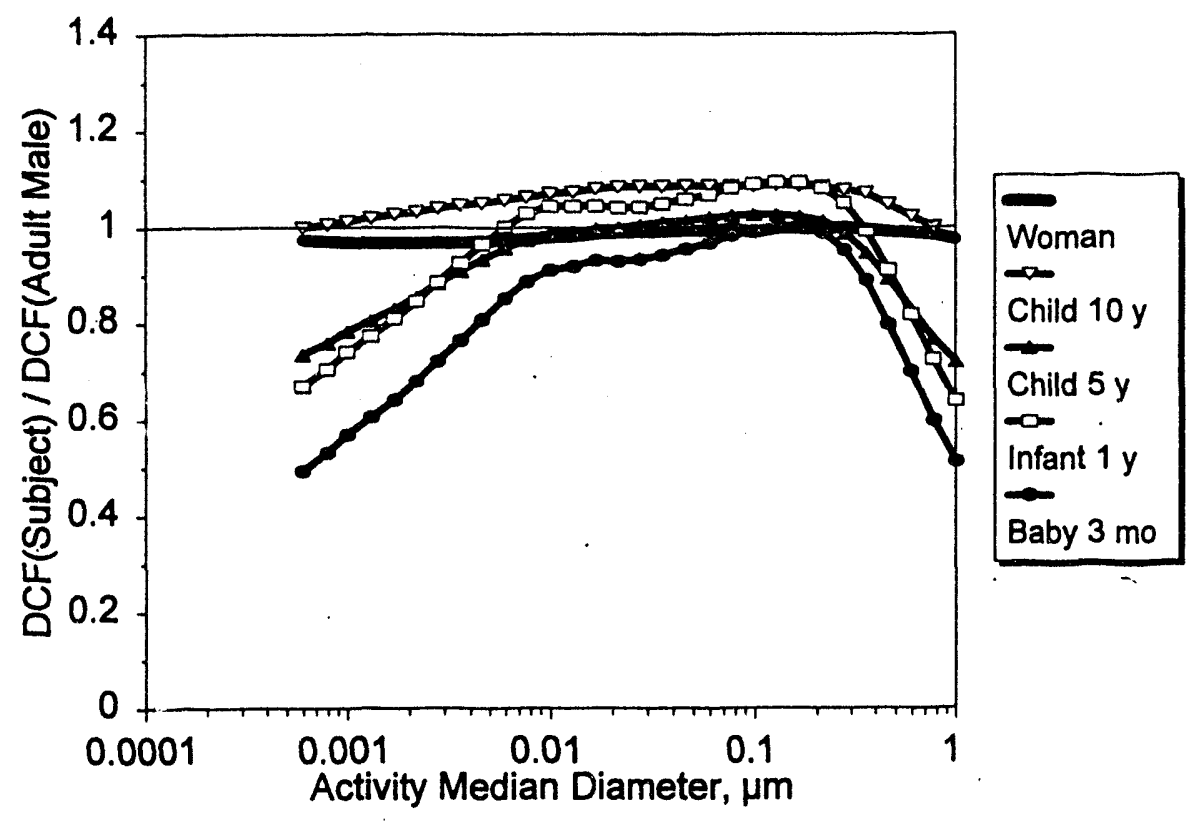

FIGURE 4. DCFs calculated for the lungs of various subjects exposed to radon progeny in the home, relative to that for an adult male.

\section{COMPARISON OF THE DCF FOR A MINER AND A HOME-DWELLER}

Figure 5 compares directly the DCF calculated as a function of particle diameter (or radonprogeny aerosol activity median diameter) for an underground miner with that calculated for an adult (male or female) exposed to radon progeny in the home. The breathing rate of the underground miner is assumed to be $1.2 \mathrm{~m}^{3} \mathrm{~h}^{-1}$ (ICRP, 1994a). Clearly, were the size distribution of the radon progeny aerosol to be the same in a home as in a mine, the lung dose per unit exposure would be lower in the home. However, the DCF varies with particle size by rather more than an order of magnitude; from a maximum of about $60 \mathrm{mGy} / \mathrm{WLM}$ for a radon 
progeny "cluster" aerosol in a mine, to a minimum of about $3 \mathrm{mGy} / \mathrm{WLM}$ for an "attached" aerosol in the home with an activity median diameter of $0.4 \mu \mathrm{m}$. After growth in the respiratory tract, the aerosol formed by cigarette smoke in room air could approach this latter extreme. For both miners and home-dwellers, the DCF for "unattached" radon progeny is approximately eightfold higher than the minimum DCF for "attached" aerosols.

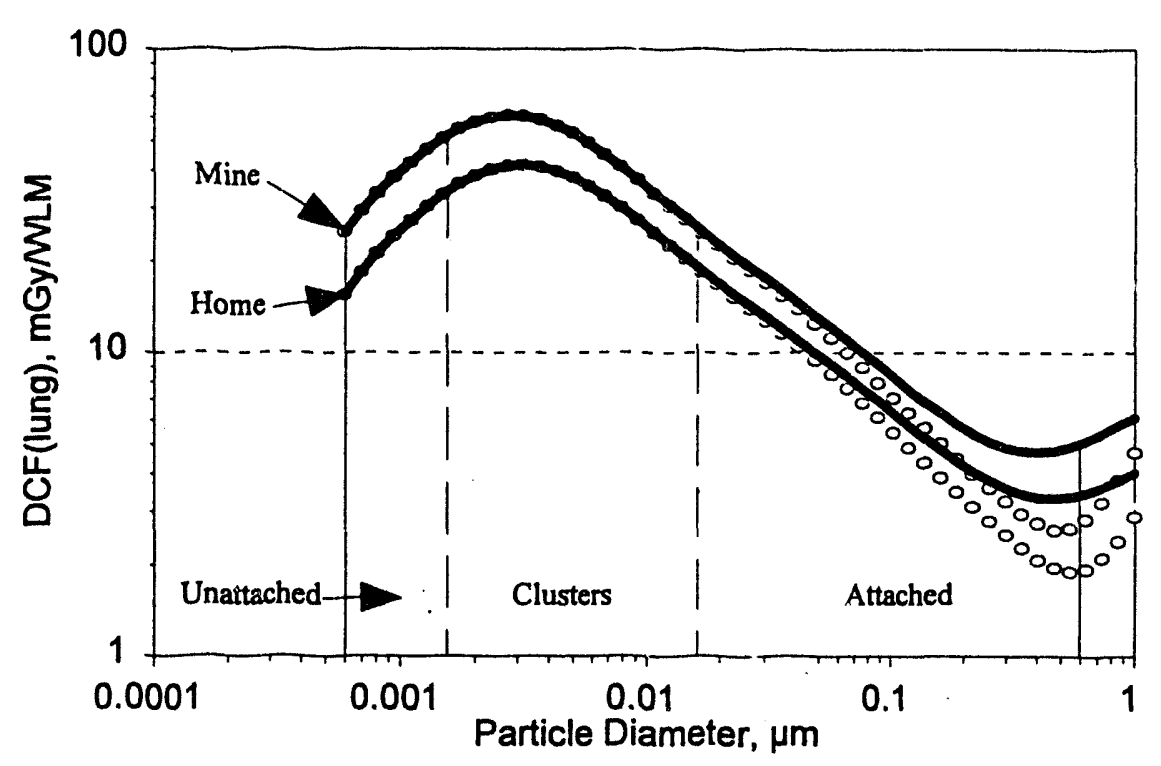

- Monodisperse Polydisperse (median)

FIGURE 5. DCFs calculated for the lungs of an underground miner (as a function of radonprogeny particle or aerosol size) compared to corresponding values calculated for a homedweller.

Comparison of the overall DCF for radon progeny in a home with that for the uranium miners exposed in the 1950s and 1960s (from whom the epidemiological estimate of lung-cancer risk was largely derived) depends crucially on being able to characterize the radon-progeny activity size distribution in both environments.

There are very few data available to define aerosol conditions in mines of the 1950s and 1960s era. The best estimate that can be achieved at present is an intelligent "guess" that the 
unattached fraction was typically low (at about $1 \%$ of potential $\alpha$ energy) and the activity median diameter of the predominantly "attached" aerosol was about $0.25 \mu \mathrm{m}$ or larger (NRC, 1991). However, Figure 5 shows that the calculated DCF has a rather flat minimum, which extends from about $0.2-0.5 \mu \mathrm{m}$ activity median diameter. Therefore, provided that substantial fractions of progeny "clusters" were not typically present in the mine air, a reasonably firm estimate of the DCF can be made. The "best estimate" is $5.6 \mathrm{mGy} / \mathrm{WLM}$, which includes $0.4 \mathrm{mGy} / \mathrm{WLM}$ contributed by exposure to "unattached" progeny (Birchall and James, in press).

Substantially better information is becoming available on the activity size distribution of radon progeny activity in homes (e.g., NRC, 1991; Tu et al., 1991; Wasiolek et al., 1992; Hopke et al., 1993; Tu et al., 1994). The database does not yet include a representative cross-section of U.S. homes, nor a systematic study of seasonal factors in different climatic regions. Rather, the radon progeny aerosol has been studied in detail in a few individual homes, together with its temporal variability. For example, Figure 6 shows the average distribution of radon-progeny potential $\alpha$ energy in intervals of particle size obtained from many measurements over several months in a home that was occupied normally (Wasiolek et al., 1992). On the average, about $8 \%$ of the potential $\alpha$ energy was present in the "unattached" state (with a median particle size of about $0.9 \mathrm{~nm}$ ). A similar total amount of potential $\alpha$ energy was associated with ultrafine progeny "clusters" (represented by the fractions measured in the particle size bins with median diameters of 2.8 and $9 \mathrm{~nm}$ ). The bulk of the potential $\alpha$ energy was associated with larger particles of the "attached" mode, including the largest fraction in the $280-\mathrm{nm}$ median diameter size-bin. Figure 6 also shows the fractions of the overall lung dose that are calculated to arise from the measured distribution of potential $\alpha$ energy in the home studied. It is seen that almost a quarter of the lung dose arises from exposure to "unattached" progeny, with a similar fraction from progeny "clusters."

One of the three occupants of this home was a cigarette smoker. Similar results were obtained in another home which housed a cigarette smoker. However, in a third home without cigarette smokers, the fraction of potential $\alpha$ energy associated with progeny "clusters" was on the average about $50 \%$ higher, and the median particle size of the "attached" aerosol was smaller 
(at about $0.1 \mu \mathrm{m}$ instead of $0.15 \mu \mathrm{m}$ ). Both of these factors point to a higher dose conversion factor in homes without smokers.

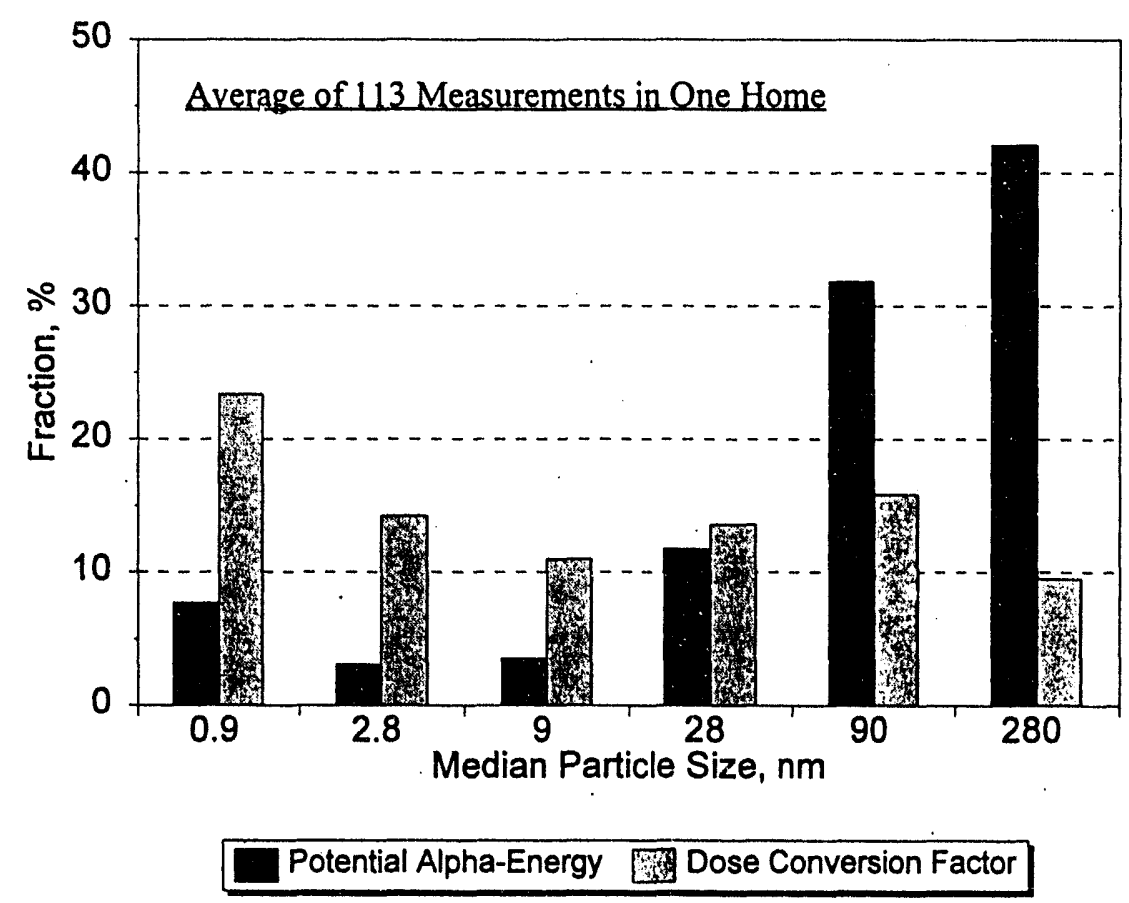

FIGURE 6. Fraction of potential $\alpha$ energy associated with different intervals of particle size in a home (with one of three occupants a cigarette smoker), compared with the corresponding fractionation of the dose conversion factor.

\section{VARIABILITY OF DOSE PER UNIT EXPOSURE IN HOMES}

Figure 7 shows the variability in the dose conversion factor with respect to exposure to potential $\alpha$ energy, denoted by $\mathrm{DCF}(\mathrm{PAE})$, observed in month-long studies in three different homes (Wasiolek et al., 1992). The DCF(PAE) is here plotted as a function of the measured fraction of potential $\alpha$ energy associated with particles smaller than $15 \mathrm{~nm}$ in diameter, denoted by $f_{p}(15)$. This fraction, which could be termed the "ultrafine" fraction, includes both "unattached" progeny and progeny "clusters." Clearly, characterizing the activity-size distribution by the parameter $f_{p}(15)$ provides an accurate measure of the variability in DCF(PAE); the coefficient 
1 of determination, $r^{2}$, is 0.9 . In comparison, the classical "unattached fraction of potential $\alpha$ 1 energy, " $f_{p}$ (where the particle size cut is taken to be $1.5 \mathrm{~nm}$ instead of $15 \mathrm{~nm}$ ), is a much weaker predictor of DCF(PAE); the corresponding value of $r^{2}$ based on the measurement of $f_{p}$ $i \quad$ is only 0.16 .

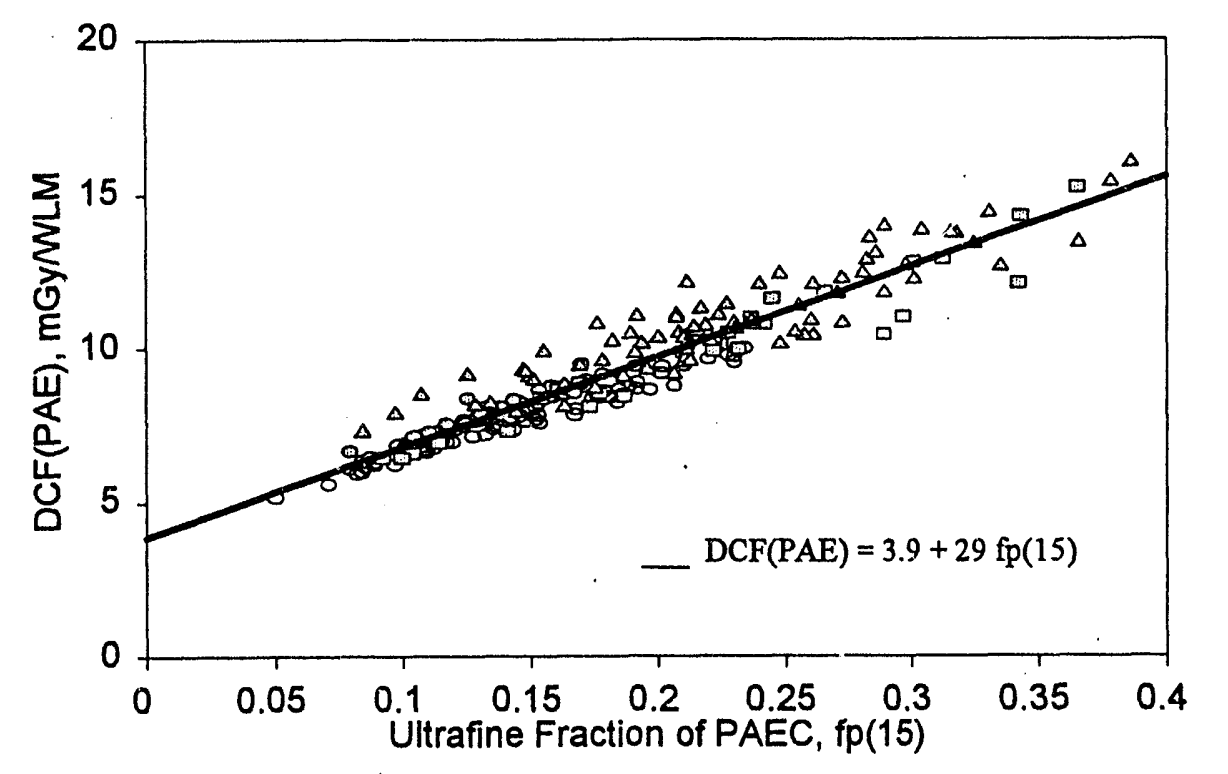

$\circ \quad \# 1(\mathrm{a}): 7.9 \pm 0.9 \circ \quad \# 1(\mathrm{~b}): 7.9 \pm 1.2 \quad$ a $\quad \# 2: 10.0 \pm 2.2 \quad \Delta \quad \# 3: 10.9 \pm 1.8$

1 FIGURE 7. Variability of the dose conversion factor with respect to potential $\alpha$-energy e exposure, $\mathrm{DCF}(\mathrm{PAE})$, as a function of the ultrafine fraction, $\mathrm{f}_{\mathrm{p}}(15)$, of the potential $\alpha$-energy c concentration (PAEC). Values shown in the key are means \pm 1 standard deviation of individual n measurements made in 3 different normally occupied homes. Two separate studies were carried c out in home \#1.

7 The data shown in Figure 7 illustrates several other important points:

ᄃ $\quad$ the dose conversion factor with respect to potential $\alpha$-energy exposure varies widely in each home (by about a factor of three overall);

ᄃ $\square$ the observations were highly repeatable in the home studied on two separate occasions (home \#1); and 
ㅁ the average value of the DCF(PAE) was substantially higher than the "best estimate" of $5.6 \mathrm{mGy} / \mathrm{WLM}$ discussed earlier in this chapter for an underground miner (by about $50 \%$ in one home, and almost double in two other homes).

\section{IMPLICATIONS FOR RISK PROJECTION}

As mentioned above, it is not yet known how applicable the results of these very detailed studies in three homes are for the housing stock of the United States as a whole (or for homes in other countries). In particular, the observations of substantially higher DCF(PAE)s in homes compared to the value estimated for an underground mine need to be confirmed by studies in a broader sample of different home types before firmer projections of risk from miners to the general public can be made. Furthermore, the sophisticated measurement techniques needed to detect the dosimetrically important ultrafine progeny "clusters" have only recently been developed (Knutson et al., 1988; Holub et al., 1988; Tu and Knutson, 1988; Tu et al., 1991; Ramamurthi and Hopke, 1991); comparable techniques were simply not available to characterize the radon progeny aerosols in 1950s and 1960s mines. A recent reanalysis of the relatively few measurements made in the $1970 \mathrm{~s}$ in diesel-operated uranium mines has indicated that progeny "clusters" were a major factor in increasing the DCF(PAE) to about $10 \mathrm{mGy} / \mathrm{WLM}$ (Knutson and George, 1992). However, it is not known how applicable these data are to the different conditions in the non-diesel operated mines of the $1950 \mathrm{~s}$ and $1960 \mathrm{~s}$. It is possible that the DCF(PAE) associated with radon-exposed miners could have been substantially higher than the current estimate of about $6 \mathrm{mGy} / \mathrm{WLM}$, but we cannot be certain without more specific information. In view of the uncertainties attached to defining a "typical" DCF(PAE) for both the historically exposed miners and for the population as a whole, the ICRP has adopted the reasonable assumption of equality (ICRP, 1994a).

\section{RELATING LUNG DOSE RATE TO RADON GAS CONCENTRATION}


In practice, exposure to radon progeny in the home is controlled in terms of the measured concentration of radon gas. Figure 8 shows the variability in the dose conversion factor with respect to radon gas concentration, denoted by $\mathrm{DCF}(\mathrm{Rn})$, derived from the measurements by Wasiolek et al. (1992) in the three homes studied in detail. The $\mathrm{DCF}(\mathrm{Rn})$ is here plotted as a function of the measured radon progeny equilibrium factor, ${ }^{2} F$. Temporal variability in the equilibrium factor accounts for less than half the observed overall variability in $\operatorname{DCF}(R n)$; the value of $r^{2}$ is 0.45 . The average value of $F$ measured in these three homes was 0.5 ( \pm 0.13 temporal standard deviation). They were therefore "tighter," i.e., less leaky, than ICRP's "reference" home, which is assumed to have an equilibrium factor of 0.4 (ICRP, 1994a). The a verage value of $\operatorname{DCF}(\mathrm{Rn})$, i.e., the calculated average dose rate to the lungs as a whole per unit radon gas concentration, was approximately $50 \mu \mathrm{Gy} / \mathrm{y}$ per $\mathrm{Bq}(\mathrm{Rn}) \mathrm{m}^{-3}$. This value is similar to the $40 \mu \mathrm{Gy} / \mathrm{y}$ per $\mathrm{Bq}(\mathrm{Rn}) \mathrm{m}^{-3}$ estimated previously for bronchial epithelium, based on comparatively primitive data (James et al., 1988).

In each of the homes studied, the temporal variability in $\mathrm{DCF}(\mathrm{Rn})$ was approximately a factor of three. This is similar to the variability in the dose conversion factor, $\mathrm{DCF}(\mathrm{PAE})$, with respect to potential $\alpha$-energy exposure discussed above. One could infer, therefore, that a measurement of the concentration of radon gas is as good an estimator of lung dose rate as a measurement of potential $\alpha$-energy concentration (PAEC). Furthermore, simple devices (passive radon detectors) enable measurements of the radon gas concentration in a home to be extended over many months.

${ }^{2}$ The equilibrium factor, $F$, is the ratio of the equilibrium equivalent concentration, $c_{\text {eq }}$, to the radon gas concentration, where $c_{e q}$ is the activity concentration of radon, in equilibrium with its short-lived progeny which would have the same potential $\alpha$ energy concentration (PAEC) as the existing non-equilibrium mixture. 


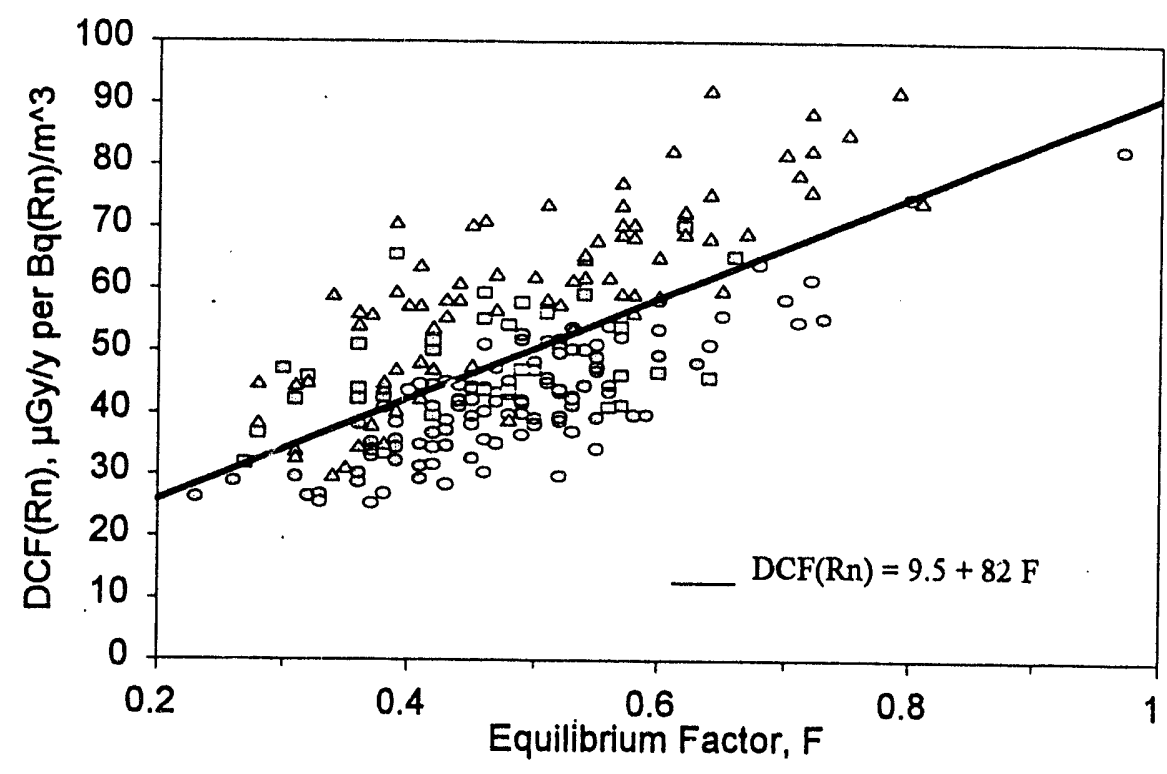

$\circ \# 1(a): 42 \pm 11 \quad \circ \quad \# 1(b): 43 \pm 9$ a \#2: $49 \pm 9 \quad \Delta \quad \# 3: 56 \pm 22$

FIGURE 8. Variability of the dose conversion factor with respect to radon gas concentration $\mathrm{DCF}(\mathrm{Rn})$, shown as a function of the measured radon progeny equilibrium factor, $F$. Values shown in the key are means \pm 1 standard deviation of individual measurements of $\mathrm{DCF}(\mathrm{Rn})$ made in the homes referred to in Figure 7.

Figure 9 shows that temporal variability of the dose rate with respect to radon gas concentration, $\mathrm{DCF}(\mathrm{Rn})$, is not closely related to the radon progeny activity-size distribution [as represented by the ultrafine fraction of potential $\alpha$-energy concentration, $\left.\mathrm{f}_{\mathrm{p}}(15)\right]$. The coefficient of determination, $r^{2}$, is 0.27 . Thus, in a particular home, variability in the equilibrium factor, $F$, seems to have a greater impact on $\mathrm{DCF}(\mathrm{Rn})$ than variability in the size distribution of the radon progeny aerosol. Overall, however, characterization of the radon progeny aerosol for a broader, more representative sample of the U.S. housing stock is still needed to define a "typical" value of the dose conversion factor with respect to radon gas concentration, its variability between different types of home, and between the homes of nonsmokers and smokers. Since the equilibrium factor of about 0.5 found by Wasiolek et al. (1992) in the three homes studied in detail is significantly higher than the value of 0.4 considered to be "typical" (ICRP, 1994a), then the "typical" values of $\mathrm{DCF}(\mathrm{Rn})$ could well be lower than the approximately $55 \mu \mathrm{Gy} / \mathrm{y}$ per 
$\mathrm{Bq}(\mathrm{Rn}) \mathrm{m}^{-3}$ derived here for one "nonsmoker" home and about $45 \mu \mathrm{Gy} / \mathrm{y}$ per $\mathrm{Bq}(\mathrm{Rn}) \mathrm{m}^{-3}$ for the two "smoker" homes.

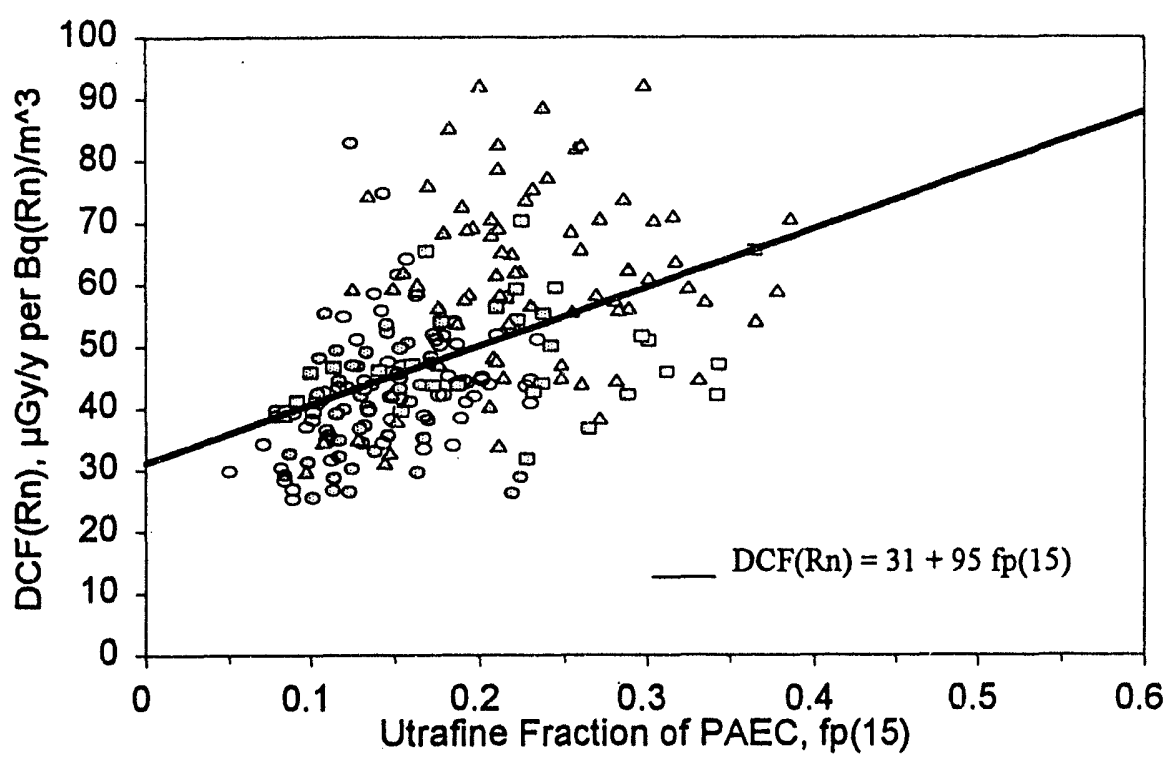

$\circ \# 1(a): 42 \pm 11 \quad \circ \quad \# 1(b): 43 \pm 9 \quad$ 口 $\# 2: 49 \pm 9 \quad \Delta \quad \# 3: 56 \pm 22$

FIGURE 9. Variability of the dose conversion factor with respect to radon gas concentration $\operatorname{DCF}(R n)$, shown as a function of the measured ultrafine fraction, $f_{p}(15)$, of the potential $\alpha$ energy concentration (PAEC).

\section{LUNG DOSE PER UNIT EXPOSURE TO THORON PROGENY}

Figure 10 compares the lung dose per unit potential $\alpha$-energy exposure, DCF(PAE), calculated for thoron progeny (as a function of aerosol activity median diameter) with that calculated for radon progeny. The values shown relate to a "reference worker," with an average breathing rate of $1.2 \mathrm{~m}^{3} \mathrm{~h}^{-1}$. It is seen that DCF(PAE) is substantially lower for thoron progeny; the ratio is a little over one-third for corresponding activity median diameter. The smaller DCF(PAE) for thoron progeny arises primarily because a large fraction of the deposited progeny are cleared 
from the bronchi and bronchioles before the $\alpha$ decays of ${ }^{212} \mathrm{Bi}$ and ${ }^{212} \mathrm{Po}$ occur; almost all of the potential $\alpha$ energy is carried by ${ }^{212} \mathrm{~Pb}$ which has a half-life of $10.6 \mathrm{~h}$ and is a $\beta$ emitter.

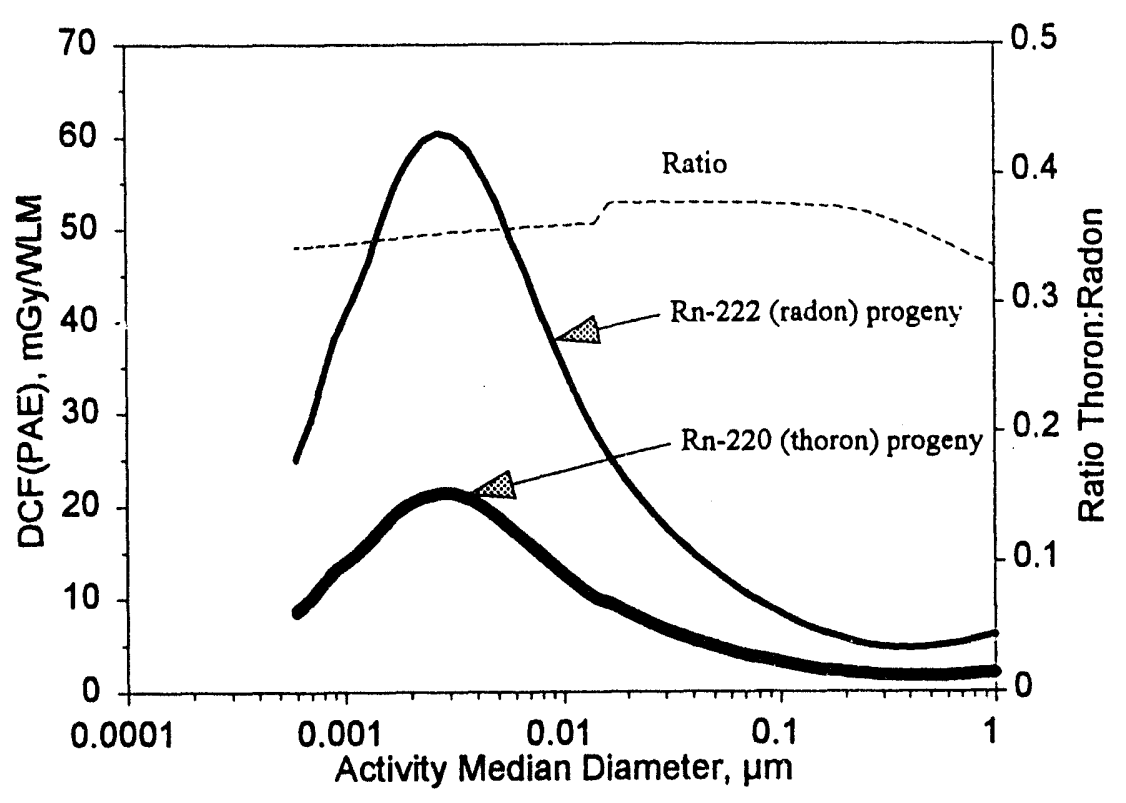

FIGURE 10. Comparison of the dose conversion factor [DCF(PAE)] with respect to potential $\alpha$-energy exposure for thoron progeny with that for radon progeny. The curves relate to a "reference worker" (average breathing rate $1.2 \mathrm{~m}^{3} \mathrm{~h}^{-1}$ ).

Limits for exposure to thoron progeny, for both occupational and domestic settings, can be derived in relation to those recommended for radon progeny by comparing the DCF(PAE); although knowledge of the "typical" aerosol characteristics of thoron progeny is even more limited than that for radon progeny (Tu et al., 1994). In general, however, it can probably be assumed that the "ultrafine" fraction of potential $\alpha$-energy is lower than that for radon progeny under the same environmental conditions.

Other organs of the body receive a more significant dose per unit exposure from thoron progeny than from radon and its progeny. However, the contribution to effective dose (primarily from 
the bone surfaces and red bone marrow, is still small in comparison to that from the lungs; the additional contribution is only about $5 \%$ (James, 1992).

\section{EXAMINATION OF EFFECTIVE DOSE FOR URANIUM MINERS}

\section{Uncertainty analysis}

Birchall and James (in press) carried out a detailed examination of the underlying assumptions made in evaluating the effective dose for uranium miners using the new ICRP respiratory tract model. They estimated the magnitude of uncertainty or variability in key parameters of the model, and represented the probability of each parameter value by a rectangular, normal, or lognormal distribution, as appropriate. In this way, uncertainties were quantified both in environmental parameters (e.g., radou-progeny activity-size distribution and degree of hygroscopic particle growth) and in respiratory tract model parameters (e.g., breathing rate, regional particle deposition, mucous thickness, depth of target cells, and the apportionment of radiation detriment between secretory or basal cells in bronchial epitheliurn and between the bronchial, bronchiolar, and alveolar-interstitial regions of the lungs).

Figure 11 shows the results of performing Latin Hypercube analyses of the frequency distribution of calculated effective dose per unit exposure $\left(E / \mathrm{P}_{\mathrm{p}}\right.$, expressed in $\left.\mathrm{mSv} / \mathrm{WLM}\right)$ for a uranium miner when the dosimetric modeling parameters were selected at random from their respective likelihood distributions. Two frequency distributions were studied: (a) that centered on ICRP's recommended regional apportionment of radiation detriment equally between bronchial, bronchiolar, and alveolar-interstitial target cells (ICRP, 1994b), and (b) that centered on the estimated baseline regional distribution of spontaneous (non-radon induced) lung cancers in the general population. For comparison, Figure 11 also shows the current "best estimate" of $5 \mathrm{mSv} / \mathrm{WLM}$, which is recommended by ICRP (1994a) as being equivalent to the projected lifetime lung-cancer risk from occupational exposure to radon 
progeny based on the uranium miner epidemiologic data. It is seen that the overall likelihood of a risk coefficient $\leq 5 \mathrm{mSv} / \mathrm{WLM}$ being obtained from the recommended methods of lung dosimetry is on the order of $1 \%$. In fact, calculated DCFs in this range are found to arise only from extreme values (or unlikely combinations) of input parameters.

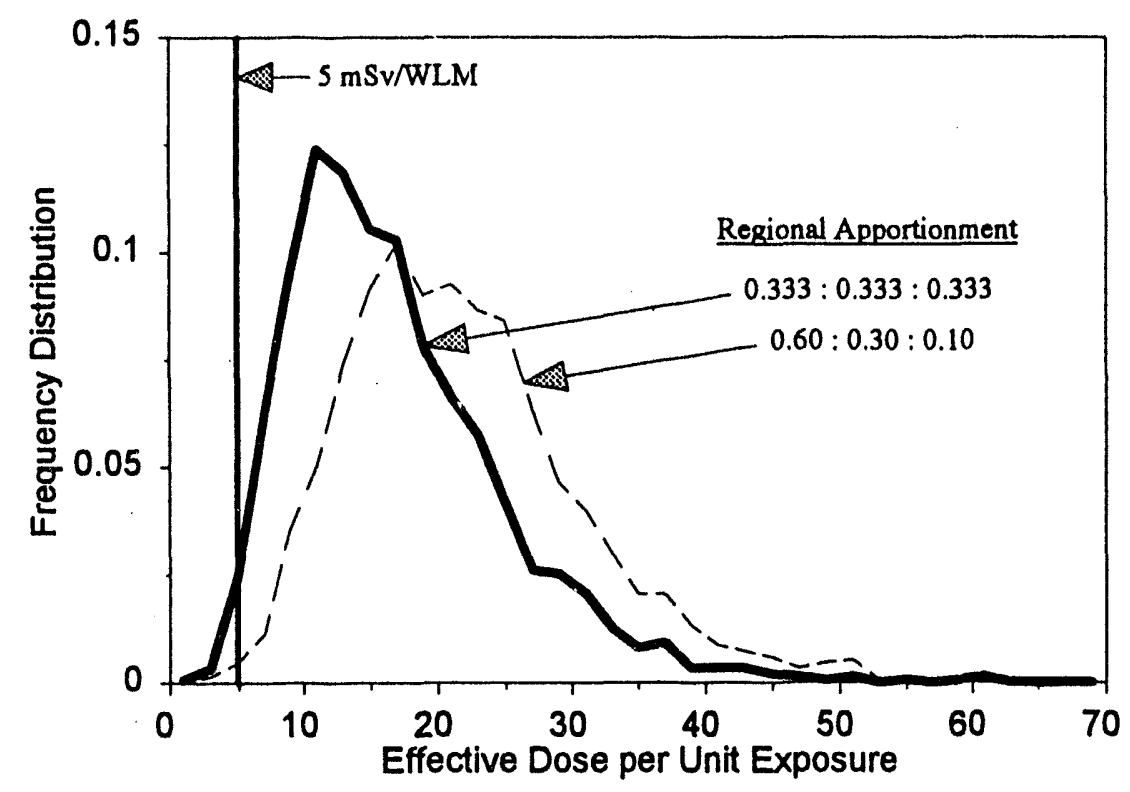

FIGURE 11. Frequency distribution of effective dose per unit exposure $\left(E / P_{p}\right)$ generated by varying all parameters and assumptions in the dosimetry calculation. Distributions are shown separately for regional apportionments centered on the ICRP recommendation of 0.333:0.333:0.333, and regional apportionment inferred from natural lung-cancer incidence.

\section{Implications for $\alpha$-emitter risk-weighting factors}

In the above analysis, no attempt was made to examine the uncertainties in each of ICRP's recommended dosimetric risk-weighting factors, which are also required to specify the effective dose. These additional parameters are: (1) the radiation weighting factor, $w_{R}$, of 20 for alpha particles; (2) the tissue weighting factor, $\mathrm{w}_{\mathrm{T}}$ of 0.12 for the lungs; (3) the total detriment coefficient at high dose rate, $\mathrm{DE}_{\mathrm{H}}$, of 0.112 per $\mathrm{Sv}$ (based on the Japanese atomic bomb-survivor studies); and (4) the dose and dose-rate effectiveness factor, DDREF, of 2 
(assumed to apply for all exposures at moderate or low dose rates). The recommended values were used to calculate the distributions of $E / \mathrm{P}_{\mathrm{p}}$ shown in Figure 11.

For ICRP's recommended equal apportionment of radiation detriment between bronchial, bronchiolar, and alveolar-interstitial tissues, the arithmetic mean of calculated $E / \mathrm{P}_{\mathrm{p}}$ is found to be $17.2 \mathrm{mSv} / \mathrm{WLM}$. However, the direct combination of central estimates of each of the input dosimetric parameters gives a lower modal estimate for $E / \mathrm{P}_{\mathrm{p}}$ of $13.4 \mathrm{mSv} / \mathrm{WLM}$. It is reasonable to take an intermediate rounded value of approximately $15 \mathrm{mSv} / \mathrm{WLM}$ to be the "best estimate" of the DCF for uranium miners based on ICRP's forthcoming dosimetric recommendations. The corresponding lifetime risk coefficient for exposure of a uranium miner that is implied by ICRP's dosimetric methodology is therefore $8.410^{-4}$ per WLM. However, the recommended value of the risk coefficient estimated directly from epidemiology of uranium miners is only $2.810^{-4}$ per WLM (ICRP, 1994a). In other words, use of ICRP's dosimetric risk-weighting factors would seem to result in an overestimate of the observed risk of lung cancer from occupational radon-progeny exposure by a factor of three.

It is useful to consider the excess lifetime risk of lung cancer directly in terms of the lung dose, i.e., the absorbed dose that has been adjusted by the regional weighting factors, together with a composite risk factor, $\Omega=\mathrm{w}_{\mathrm{T}}^{\text {lung }} \mathrm{w}_{\mathrm{R}}^{\alpha} \mathrm{DE}_{\mathrm{H}} / \mathrm{DDREF}$ (Birchall and James, in press). If the ICRP recommended values for each of the primary risk-weighting factors are used, then the value of $\Omega$ is $0.1344 \mathrm{~Gy}^{-1}$. However, if the epidemiologic risk estimate of 2.8 $10^{-4}$ is taken, together with the best estimate of $E / \mathrm{P}_{\mathrm{p}}$ of $15 \mathrm{mSv} / \mathrm{WLM}$, i.e., a regionally weighted lung dose of $6.25 \mathrm{mGy} / \mathrm{WLM}$, then this implies a value of $\Omega$ of approximately 0.05 $\mathrm{Gy}^{-1}$. Furthermore, if this implication is accepted for radon-progeny exposure, and there is no reason to suppose that $\boldsymbol{\Omega}$ is specific to radon progeny, then:

$\square$ the risk factor $\Omega \approx 0.05 \mathrm{~Gy}^{-1}$ should also apply for any alpha-emitting radionuclide in the lungs. 


\section{Normalization of calculated effective dose}

An alternative method of basing the lung cancer risk estimate directly on calculated lung dose (using the ICRP respiratory tract model) and yet avoiding the threefold overestimation introduced by applying the currently recommended dosimetric risk factors would be to introduce a dimensionless "normalization" factor. Based on the comparison of "dosimetric" and "epidemiologic" risk estimates for underground miners, the "normalization" factor should have the rounded value of 0.3 .

\section{POTENTIAL BENEFTTS OF AIR CLEANING}

To conclude this chapter, I will illustrate the application of lung dosimetry to examine the degree to which changing the atmospheric composition and concentrations of radon progeny can affect lung dose and thus lung cancer risk. I will take as my database the study by Hopke et al. (1993) of the effects of three different types of air cleaner on the radon progeny aerosol concentration and activity-size distribution when operated in a normally-occupied home.

Figure 12 shows the effects of the three air cleaners on the $\operatorname{DCF}(\mathrm{Rn})$ calculated with respect to the radon gas concentration. The $\operatorname{DCF}(\mathrm{Rn})$ considered here is the effective dose rate per unit radon gas concentration, where the "normalization" factor of 0.3 discussed above has been applied to the calculated equivalent lung dose. The devices tested were (1) the NORAD air ionizer system, with a $2.8 \mathrm{~m}^{3} \mathrm{~min}^{-1}$ fan (Moeller et al., 1988); (2) an electronic (electrostatic) air cleaner, with a $3.9 \mathrm{~m}^{3} \mathrm{~min}^{-1}$ fan; and (3) a high-efficiency room air filter, operated at a filtration rate of either 4.3 or $2.3 \mathrm{~m}^{3} \mathrm{~min}^{-1}$. 


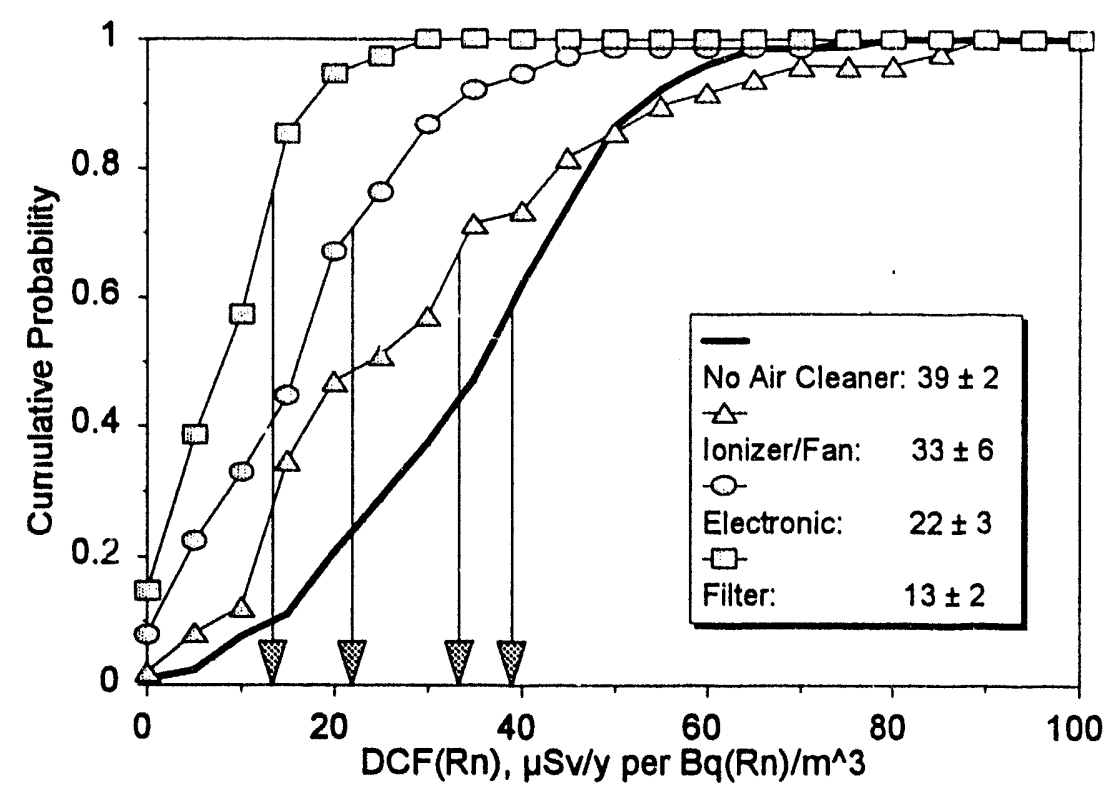

FIGURE 12. Cumulative frequency distribution (grouped data) of the conversion factor, $\mathrm{DCF}(\mathrm{Rn})$, with respect to radon gas concentration, showing the effects of operating three different types of air cleaner. The measurements were made in home \#3 for which other data were shown in Figures 7-9. The values shown in the legend are means $\pm 95 \%$ confidence intervals.

On the average, the $\mathrm{DCF}(\mathrm{Rn})$ was reduced from the value of $39 \mu \mathrm{Sv} / \mathrm{y}$ per $\mathrm{Bq}\left({ }^{222} \mathrm{Rn}\right) / \mathrm{m}^{3}$ in the absence of air cleaning, to $33 \mu \mathrm{Sv} / \mathrm{y}$ per Bq( $\left.{ }^{22} \mathrm{Rn}\right) / \mathrm{m}^{3}$ by the ionizer/fan device, $22 \mu \mathrm{Sv} / \mathrm{y}$ per $\mathrm{Bq}\left({ }^{222} \mathrm{Rn}\right) / \mathrm{m}^{3}$ by the electronic air cleaner, and $13 \mu \mathrm{Sv} / \mathrm{y}$ per $\mathrm{Rq}\left({ }^{222} \mathrm{Rn}\right) / \mathrm{m}^{3}$ by highefficiency filtration. The effects of these devices on "unattached" progeny, progeny "clusters," and progeny "attached" to larger airborne particles were found to be quite different (for discussion see Hopke et al., 1993; James et al., 1994). Therefore, both the relative and absolute effectiveness of these air cleaners for dose reduction in a particular home environment will depend on the distribution of PAEC between unattached, clustered, and attached radon progeny. In the home studied here, the relatively high proportion of PAEC normally present in the form of progeny clusters (13\%) was an important factor in achieving a threefold dose reduction by high-efficiency filtration; this technique was effective at removing clustered as well as attached progeny. 
Acknowledgement - This work was supported by the U.S. Department of Energy under Contract DE-AC06-76RLO 1830 with Battelle Memorial Institute.

\section{REFERENCES}

Birchall, A.; James, A. C. Uncertainty analysis of the effective dose per unit exposure from radon progeny and implications for ICRP risk-weighting factors. Radiat. Prot. Dosim; in press.

Holub, R. F.; Knutson, E. O.; Solomon, S. B. Tests of the graded wire screen technique for measuring the amount and size distribution of unattached radon progeny. Radiat. Prot. Dosim. 24:265-268; 1988.

Hopke, P. K.; Montassier, N.; Wasiolek, P. An evaluation of the effectiveness of several air cleaners for reducing the hazard from indoor radon progeny. Aerosol Sci. \& Technol. 19:268-278; 1993.

International Commission on Radiological Protection. 1990 Recommendations of the International Commission on Radiological Protection. Oxford: Pergamon Press; ICRP Publication 60; Ann. ICRP 21(1/3); 1991.

International Commission on Radiological Protection. Protection against radon-222 at home and at work. Oxford: Pergamon Press; ICRP Publication 65; Ann. ICRP 23(2); 1994a.

International Commission on Radiological Protection. Human respiratory tract model for radiological protection. Oxford: Pergamon Press; ICRP Publication 66; Ann. ICRP 24(1/4); 1994b. 
James, A. C.; Strong, J. C.; Cliff, K. D.; Stranden, E. The significance of equilibrium and attachment in radon daughter dosimetry. Radiat. Prot. Dosim. 24:451-455; 1988.

James, A. C. Dosimetry of radon and thoron exposures: Implications for risks from indoor exposure. In: Indoor radon and lung cancer: Reality or myth? Ed. F. T. Cross (Columbus, OH; Battelle Press); pp. 167-198; 1992.

James, A. C; Birchall, A.; Thrall, K. D.; Hui, T. E.; Briant, J. K.; Hopke, P. K.; Wasiolek, P. T. Dosimetry and aerosol technology of radon progeny. In: Pacific Northwest Laboratory Annual Report for 1993 to the DOE Office of Energy Research, Part 1, Biomedical Sciences; PNL-9000 Pt. 1; UC-408. Richland, WA; Pacific Northwest Laboratory; pp. 69-76; 1994.

Knutson, E. O.; Tu, K. W.; Solomon, S. B.; Strong, J. C. Intercomparison of three diffusion batteries for the measurement of radon decay product particle size distributions. Radiat. Prot. Dosim. 24:261-264; 1988.

Knutson, E. O.; George, A. C. Reanalysis of data on particle size distribution of radon progeny in uranium mines. In: Indoor Radon and Lung Cancer: Reality or Myth? Ed. F. T. Cross. Columbus, OH; Battelle Press; pp. 149-164; 1992.

Land, C. E.; Sinclair, W. K. The relative contributions of different organ sites to the total cancer mortality associated with low-dose radiation exposure. In: Risks Associated with Ionising Radiations. Oxford: Pergamon Press; ICRP Publication 60; Ann. ICRP 21(1/3):3157; 1991.

Lubin, J. H.; Boice, J. D.; Edling, C.; Hornung, R. W.; Howe, G.; Kunz, E.; Kusiak, R. A.; Morrison, H. I.; Radford, E. P.; Samet, J. M.; Tirmarche, M.; Woodward, A.; Xiang Y. S.; Pierce, D. A. Radon and lung cancer risk: A joint analysis of 11 underground miner studies. Bethesda, MD: National Institutes of Health; NIH Publication No. 94-3644; 1994. 
Moeller, D. W.; Rudnick, S. N.; Mayer, E. F. Laboratory and field tests of a Hassock fanion generator radon decay product removal unit. Radiat. Prot. Dosim. 24:503-506; 1988.

National Research Council (NRC). Comparative dosimetry of radon in mines and homes. Washington, DC: National Academy Press; 1991.

Ramamurthi, M; Hopke, P. K. An automated, semicontinuous system for measuring indoor radon progeny activity-weighted size distributions, $\mathrm{d}_{\mathrm{p}}: 0.5-500 \mathrm{~nm}$. Aerosol Sci. \& Technol. 14:82-92; 1991.

Tu, K. W.; Knutson, E. O.; Indoor radon progeny particle size measurements made with two different methods. Radiat. Prot. Dosim. 24:251-255; 1988.

Tu, K. W.; Knutson, E. O.; George, A. C. Indoor radon progeny aerosol size measurements in urban, suburban, and rural regions. Aerosol Sci. \& Technol. 15:170-178; 1991.

Tu, K. W.; Knutson, E. O.; George, A. C. Thoron versus radon: comparison of measured progeny aerosol size distributions.' Aerosol Sci. \& Technol. 20:266-274; 1994.

Wasiolek, P.; Hopke, P. K.; James, A. C. Assessment of exposure to radon progeny in realistic living conditions. J. Exposure Anal. \& Environ. Epidemiol. 2:309-322; 1992. 

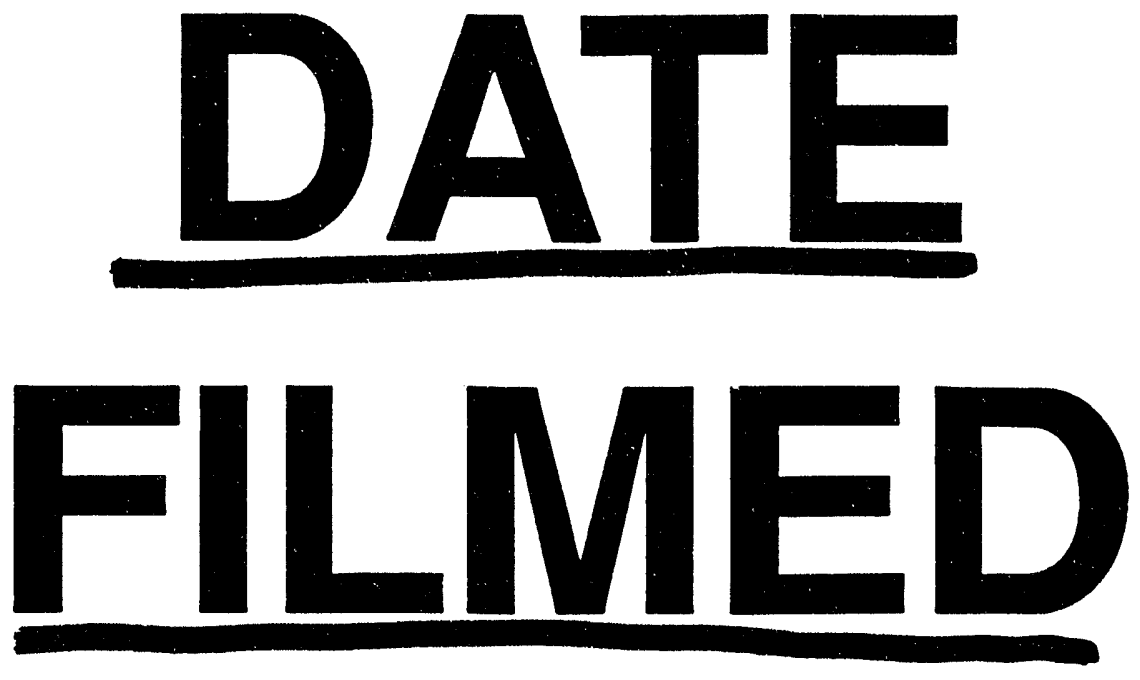

$8 / 26 / 94$
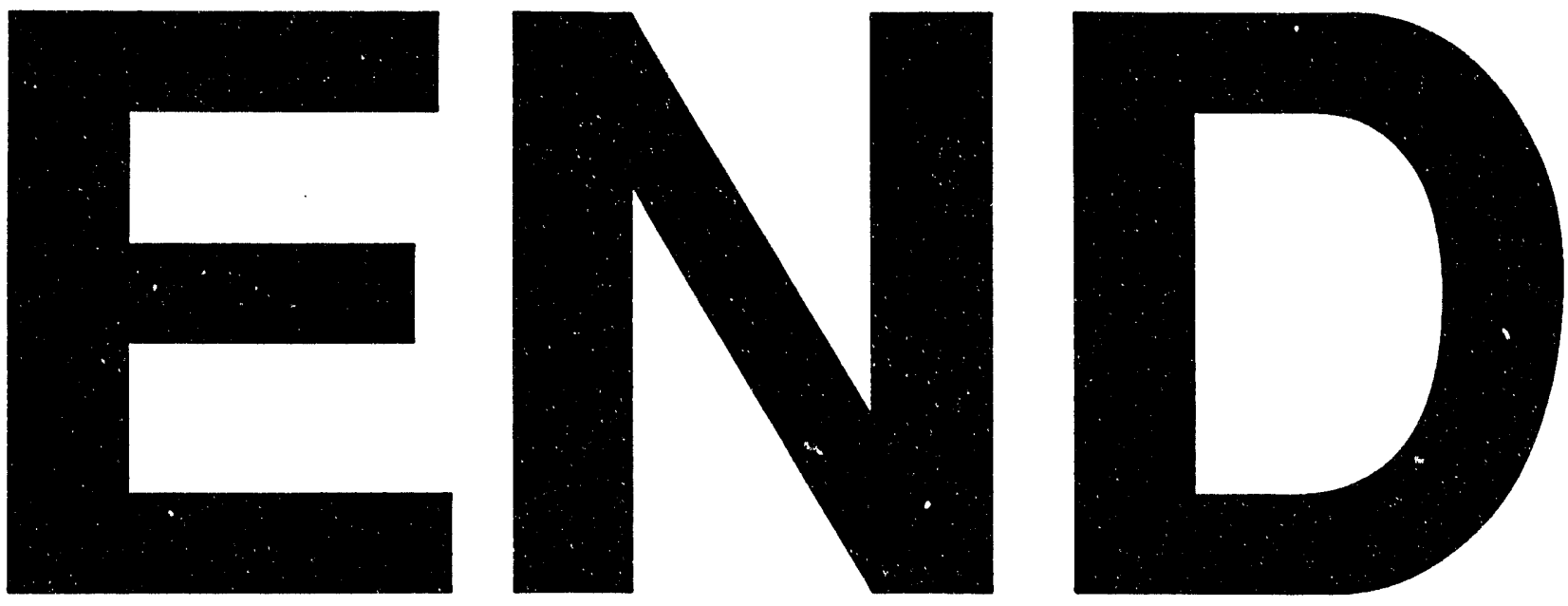
